\title{
Acute knee joint rupture after yttrium 90 injection
}

\author{
P. DAVIS AND M. I. V. JAYSON \\ From the Department of Medicine, University of Bristol, and the Royal National Hospital for Rheumatic \\ Diseases, Bath
}

\begin{abstract}
Davis, P., and Jayson, M. I. V. (1975). Annals of the Rheumatic Diseases, 34, 62. Acute knee joint rupture after yttrium 90 injection. Two cases of acute rupture of the knee joint are reported after the intra-articular injection of radioactive yttrium 90 . It is suggested that this may be a complication of intra-articular radioactive injections.
\end{abstract}

The injection of radioactive colloids into rheumatoid joints has proved to be a significant advance in the treatment of this disease. After the use of ${ }^{198} \mathrm{Au}$ (Ansell, Crook, Mallard, and Bywaters, 1963), yttrium $90\left({ }^{90} \mathrm{Y}\right)$ is now widely accepted as the most satisfactory agent. The advantages of this therapy and the most satisfactory technique have been fully reviewed (Gumpel, 1974). Complications do occur but are uncommon. In a series of 1240 injections, Menkes, Aignan, Galmiche, and Le Go (1972) reported a $4 \%$ incidence of adverse reactions, which included fever and malaise, skin rashes, and needletrack burns. The possibility that neoplastic change might occur has yet to be evaluated in long-term follow-up studies.

Not previously reported has been the complication of acute joint rupture following ${ }^{90} \mathrm{Y}$ injection. We report two such cases which have occurred after ${ }^{90} \mathrm{Y}$ administration in our unit.

\section{Method}

A standard routine is used with ${ }^{90} \mathrm{Y}$ treatment. Patients are admitted on day 1 and the joint aspirated and injected with local steroid on day $2.4 \mathrm{mCi}$ of ${ }^{90} \mathrm{Y}$ are injected into knees with the usual technical safeguards on day 4 , and the joint immobilized for a further 3 days before mobilization and discharge.

\section{CASE REPORTS}

Case 1

A 53-year-old woman had suffered from seropositive, erosive, nodular rheumatoid arthritis for 5 years. Her disease was mildly active with the exception of her knees which were painful, with soft tissue swelling and large effusions but no popliteal cysts. Treatment with ${ }^{90} \mathrm{Y}$ was carried out in the routine way and the patient discharged 4 days after injection.

The patient was readmitted 43 days after injection with painful swelling of the left calf associated with ankle oedema. Clinically there was little evidence of joint inflammation and no evidence of a popliteal cyst. The joint was aspirated and the fluid found to be sterile. An arthrogram confirmed acute joint rupture.

Case 2

A 61-year-old woman with seropositive erosive RA for 3 years was admitted for ${ }^{90} \mathrm{Y}$ injection to her left knee after successful treatment of her right knee 3 months previously. The knee was inflamed with soft tissue swelling and a large effusion, but without evidence of a popliteal cyst. A routine injection was performed and the patient discharged 6 days afterwards.

The patient was admitted 63 days after treatment with? signs of an acute joint rupture with little evidence of active synovitis or a popliteal cyst. The fluid aspirated was sterile and contained numerous polymorphs. An arthrogram confirmed the diagnosis.

\section{Discussion}

Acute joint rupture of the knee in rheumatoid arthritis is a well-recognized complication (Dixon and Grant, 1964). This is recognized as occurring in early involvement of the joint and is due to a combination of a rise in intra-articular pressure and a weakness in capsular resistance (Jayson, Swannell, Kirk, and Dixon, 1969). Although not previously reported, we have seen two cases in which acute joint rupture occurred in association with ${ }^{90} \mathrm{Y}$ injection. In both cases there was a significant delay between the injection and the joint rupture which makes it unlikely to be due to direct puncture of the joint or to an acute inflammatory response to the injection. In addition, neither case showed clinical evidence of local sepsis or acute inflammation.

As ${ }^{90} \mathrm{Y}$, with a half-life of 2.7 days, was particularly chosen because of its slow clearance rate from joints with a mean retention of $91 \%$ at 5 days (Ramsey, 1973), it is possible that the presence of a radioactive substance sets up a chronic inflammatory response 
leading to rupture. Alternatively localized capsule necrosis secondary to radiation may occur with eventual rupture.
It is possible, therefore, that in these two cases joint rupture was directly associated with the intraarticular injection of radioactive material.

\section{References}

Ansell, B. M., Crook, A., Mallard, J. R., AND Bywaters, E. G. L. (1963) Ann. rheum. Dis., 22, 435 (Evaluation of intra-articular colloidal gold $\mathrm{Au} 198$ in the treatment of persistent knee effusions)

Dixon, A. ST. J., AND GRANT, C. (1964) Lancet, 1, 742 (Acute synovial rupture in rheumatoid arthritis)

GuMPEL, J. M. (1974) Rheum. and Rehab., 13, 1 (The role of radio-colloids in the treatment of arthritis)

Jayson, M. I. V., Swannell, A. J., KIRK, J. A., AND Dixon, A. St. J. (1969) Ann. phys. Med., 10, 175 (Acute joint rupture)

Menkes, C. J., Aignan, M., Galmiche, B., ANd Le Go, A. (1972) Supplement to Rheumatologie, 2, 61 (Le traitement des rheumatises par les synoviorthèsis)

Ramsey, N. W. (1973) Ann. rheum. Dis., 32, Suppl., 38 (Retention of ${ }^{90} \mathrm{Y}$ in patients with rheumatoid arthritis) 